\title{
Как упростить процедуры согласования при создании и применении ЭКБ для заявителей
}

III Научно-техническая конференция ФГУП «МНИИРИП»

«Многофункциональный центр радиоэлектроники единое отраслевое информационное окно»

Ю. Ковалевский

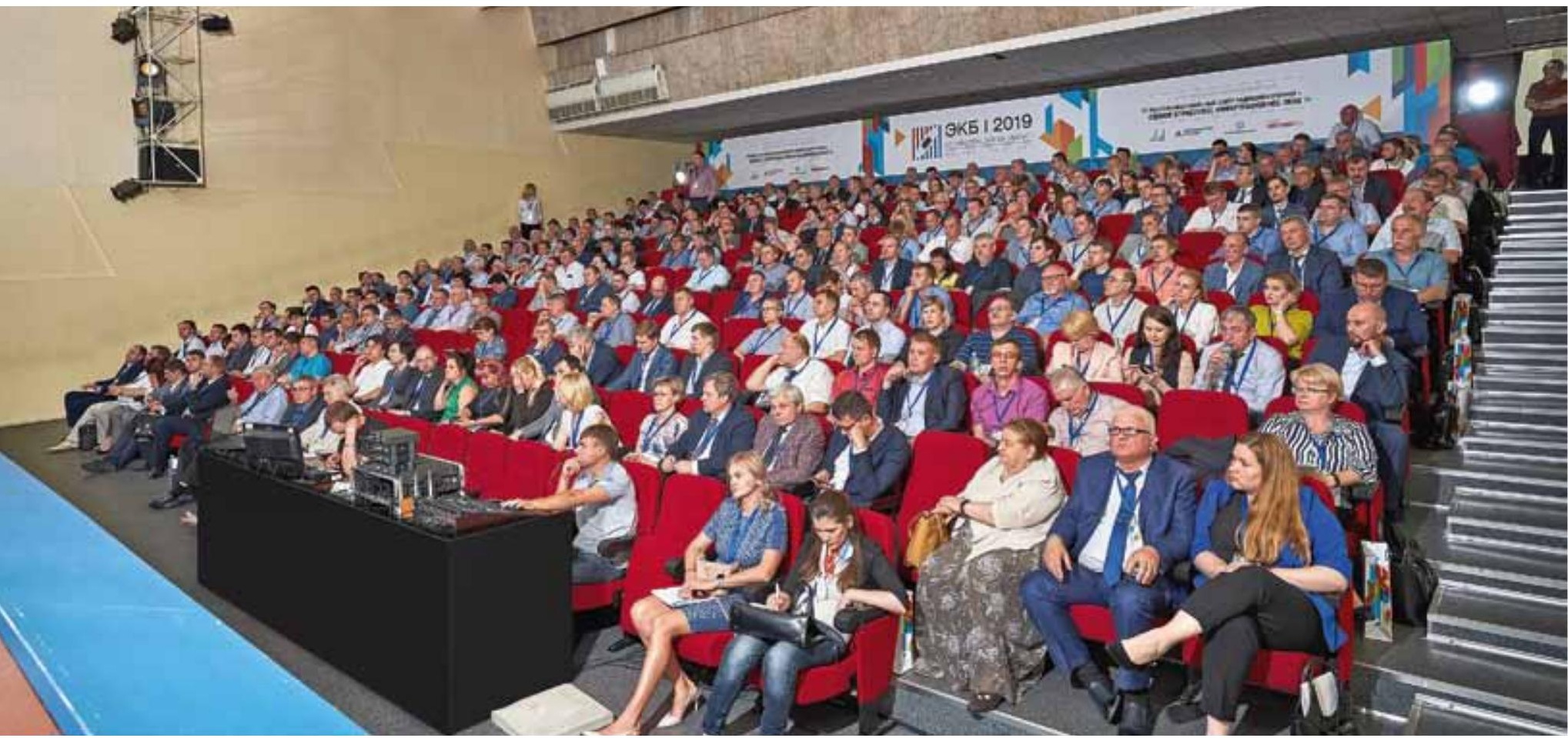

В настоящее время многие предприятия сталкиваются со сложностями при получении необходимых согласований и разрешений, связанных с разработкой и применением новых изделий ЭКБ, что негативно сказывается на сроках выполнения работ, внедрении передовых решений и ходе импортозамещения электронных компонентов. ФГУП "МНИИРИП" предлагает решение этой проблемы - создание на базе института Многофункционального центра радиоэлектроники как единого отраслевого информационного окна. Этой теме была посвящена III Научно-техническая конференция ФГУП "МНИИРИП", состоявшаяся 30-31 мая 2019 года.

начале мероприятия к присутствующим обратился директор Фгуп "МнИИРИП" П. П. Куцько, отметив, что институт претворяет в жизнь план по проведению по меньшей мере раз в год конференций, которые призваны не только знакомить представителей отрасли с предложениями и нововведениями ФГУП «МНИИРИП» в части организации разработки, производства и применения ЭКБ, но и отчитываться о выполнении решений предыдущих конференций. 
Далее П. П. Куцько передал слово для открытия мероприятия заместителю председателя коллегии Военно-промышленной комиссии Российской Федерации О.И.Бочкарёву, который в своем вступительном слове отметил важность системной работы, проводимой в настоящее время ФГУП «МНИИРИП» в отно-

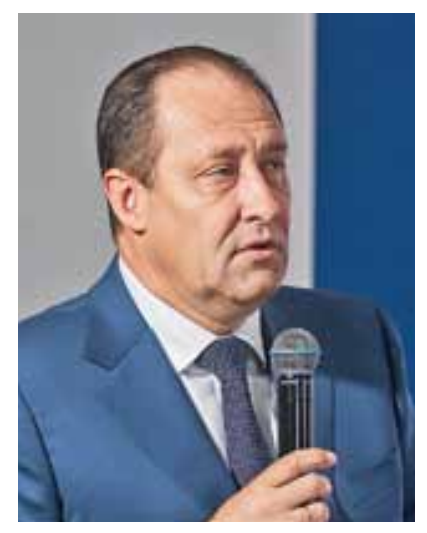

шении координации, организации коммуникаций между предприятиями отрасли и органами исполнительной власти, а также информационного обеспечения промышленности, частью которой является проведение подобных конференций.

Также О.И. Бочкарёв охарактеризовал как правильный путь создание институтом торгово-информационной площадки "ЭКБ МАРКЕТ» и выразил надежду, что в скором будущем эта площадка станет маркетплейсом мирового уровня, выступая в роли не просто источника информации, но системы бизнеса. Важность этой площадки обусловлена еще и тем, что ЭКБ находится в самом конце цепочки поставок в рамках кооперации, и на практике достоверная информация о планировании заказов и их объемах доходит до производителей слишком долго. Такая площадка может стать инструментом решения этой проблемы, способствуя более эффективной организации работы по обеспечению заказчиков ЭКБ в установленные сроки, включая более планомерную загрузку производства.

Говоря о других проблемах отрасли, требующих решения, О. И. Бочкарёв отметил задержки, связанные с согласованием расчетно-калькуляционных материалов, и призвал присутствующих приложить усилия для устранения этих задержек по крайней мере в связке поставщик ЭКБ производитель приборов.

Следующая обозначенная проблема - возрастающие сложности с применением ЭКБ иностранного производства (ИП), в том числе касающиеся роста объемов контрафактной продукции и подмены в поставках ЭКБ компонентами другого назначения с менее жесткими требованиями к параметрам. Эта ситуация требует высокой дисциплины при использовании зарубежной ЭКБ и взвешенного подхода к объемам ее входного контроля в тех случаях, когда применения ЭКБ ИП невозможно избежать.

В качестве важного вопроса О.И. Бочкарёв выделил и формирование новой бизнес-модели отрасли, направленной в том числе на сокращение сроков выполнения заказов на изготовление ЭКБ, призвав представителей отраслевых предприятий вносить свои предложения, чтобы решение этой задачи было основано на мнении практических специалистов - профессионалов отрасли.

В завершение своего выступления О.И. Бочкарёв обратил внимание представителей организаций - производителей ЭКБ, выполняющих работы в рамках гособоронзаказа, на низкое качество предоставления отчетности по раздельному учету затрат и указал на необходимость принятия мер внутри предприятий для устранения этой проблемы.

Затем П. П. куцько представил доклад, посвященный теме $\mathrm{KOH}^{-}$ ференции - планам ФгУП «МНИИРИП» по созданию Многофункционального центра радиоэлектроники - единого отраслевого информационного окна.

Докладчик сообщил, что к этой идеи привели положительные результа-

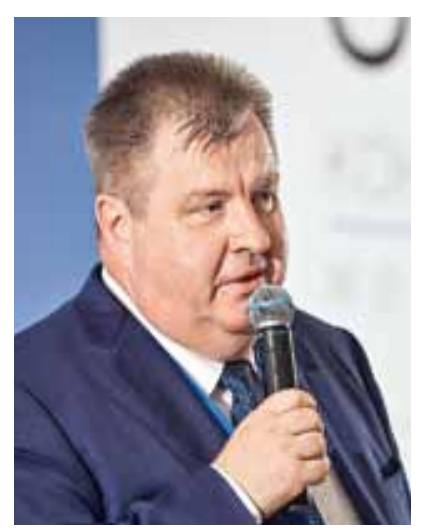
ты создания Многофункциональных центров (МФЦ), оказывающих в режиме одного окна государственные услуги гражданам. Эти результаты каждый из нас может оценить, заметив, насколько упростилось с появлением МФЦ получение таких услуг, как, например, оформление заграничного паспорта.

Как отметил П.П. Куцько, человечество движется в сторону упрощения выполнения различных процедур. Вместе с тем, порой действия в части обеспечения деятельности предприятий электронной и радиоэлектронной промышленности похожи на лабиринт с множеством вопросов, на которые непонятно где и как искать ответы. Это происходит из-за недостатка четких регламентов проведения соответствующих процедур, и решение данной проблемы позволит не только ускорить их выполнение за счет снижения влияния субъективных оценок, устранения бюрократических проволочек и других необоснованных задержек, но также сократить финансовые потери и снизить коррупционные риски.

Предложение ФГУП «МНИИРИП» заключается в организации сервиса одного окна, основанного на прозрачных регламентах с установленными сроками выполнения, который обеспечит простой и понятный алгоритм действий заявителя для получения любой из оказываемых услуг: подготовить пакет документов, сдать их в единое окно в порядке электронной очереди и по истечении установленного регламентом срока получить документы, готовые к дальнейшему использованию. При этом ФГУП «МНИИРИП» берет на себя выполнение всех задач по необходимому согласованию 
документов со всеми федеральными органами исполнительной власти.

Кроме того, П. П. Куцько отметил роль ЭКБ как основы радиоэлектронной отрасли и промышленности в целом и указал на готовность ФГУП «МНИИРИП» определить потребности в отечественной ЭКБ для реализации госпрограмм и национальных проектов.

Также в докладе было уделено внимание планам института по организации Центра коллективного пользования, которые отвечают задачам создания новых дизайн-центров, обозначенных заместителем Председателя Правительства РФ Ю.И. Борисовым. В данном центре могут быть собраны библиотеки ЭКБ, нормативная документация, ІР-блоки, используемые при разработке ЭКБ, а также обеспечены валидация и верификация математических моделей ЭКБ для САПР и установлен комплекс программных продуктов для использования предприятиями отрасли.

Далее П. П. Куцько рассказал о реализации планов, обозначенных на предыдущих конференциях института: создании и развитии торгово-информационной площадкИ «ЭКБ МАРКЕТ» и Интегрированного испытательного центра.

Докладчик привел ряд цифр по регистрации пользователей на площадке "ЭКБ МАРКЕТ», разработанной ФГУП «МНИИРИП» в сотрудничестве с Группой компаний Остек и АО «ЦНИИ "Электроника». Так, по состоянию на 30 мая 2019 года на площадке было зарегистрировано более 1300 пользователей, представляющих 636 предприятий. П. П. Куцько назвал отрадным то, что в структуре пользователей «ЭКБ МАРКЕТ» 58,1\% составляют потребители ЭКБ - именно те, для кого эта площадка создавалась, а тот факт, что 40,5\% пользователей - инженеры, а 39,7\% - руководство среднего звена, указывает на то, что на площадке регистрируются специалисты, непосредственно работающие с ЭКБ, то есть регистрация не является формальной.

На площадке постоянно расширяется набор сервисов. На данный момент организован доступ к каталогам ЭКБ отечественного производства, организуется размещение Ту и технических описаний, начато размещение библиотеки 3D-моделей отечественной ЭКБ и проч. Одним из важных сервисов было названо предоставление информации об остатках на складах, которая начинает поступать от производителей и поставщиков ЭКБ. Среди ближайших планов развития - наполнение площадки информацией о ведущихся ОКР в части ЭКБ, для чего уже предусмотрен соответствующий функционал. Также планируется создание закрытого контура "ЭКБ МАРКЕТ».

П. П. Куцько рассказал и о взаимодействии с другими информационными системами, среди которых системы ГК «Роскосмос» и ГК «Росатом».
На площадке также реализован функционал Интегрированного испытательного центра, о планах создания которого было заявлено на второй конференции института в мае 2018 года, и ведется его наполнение информацией о действующих аккредитованных испытательных центрах. Данный сервис предоставляет возможность достаточно простого размещения заявки на проведение испытаний и получения информации об испытательных центрах, которые по своим возможностям соответствуют данной заявке, что обеспечивает эффективность взаимодействия предприятий с испытательными центрами, а также повышает оперативность организации испытаний и качество их проведения.

В процессе доклада П. П. Куцько отметил, что немногим более года назад, когда на первой конференции ФГУП «МНИИРИП» было рассказано о планах по созданию торгово-информационной площадки «ЭКБ MAPКЕТ", многие отнеслись к этой инициативе скептически, обосновывая это тем, что компании и предприятия отрасли не будут проявлять активного участия в работе этой площадки: несмотря на недостатки существующей системы отношений, к ней все привыкли и не будут заинтересованы в новых инструментах. Однако практика показала, что площадка успешно развивается, на ней открываются новые сервисы, постоянно растет количество ее пользователей, и многие задачи, которые раньше казались почти неподъемными, "ЭКБ МАРКЕТ» позволяет решать просто и эффективно. Также успешно идет реализация планов по организации на площадке Интегрированного испытательного центра - темы второй конференции ФГУП «МНИИРИП». Всё это, по сути, является ответом на вопрос о том, почему должны реализоваться новые амбициозные планы института по созданию Многофункционального центра радиоэлектроники

Следует отметить, что, несмотря на ряд заданных докладчику вопросов, касавшихся некоторых «подводных камней" и выражавших сомнение в отдельных аспектах работы будущего единого окна, аудитория восприняла данную инициативу с энтузиазмом и верой в исполнение институтом намеченных планов.

Доклад П. П. Куцько и заданные ему вопросы аудитории прокомментировал О. И. Бочкарёв, высказав ряд предложений по совершенствованию площадки “ЭКБ МАРКЕТ", среди которых были наполнение площадки информацией о дизайн-центрах и организация взаимодействия с информационной системой ГИСП.

Также О.И. Бочкарёв указал на полезность информации об остатках электронных компонентов на складах, которую могут выкладывать на площадку не только производители и поставщики, но и потребители ЭКБ. У потребителей такие остатки могут возникать по различным причинам, в том числе связанным 
с минимальными объемами заказа конкретного типономинала, а учитывая ограниченные сроки годности и длительность поставок некоторых типов компонентов, использование этой возможности может существенно повысить эффективность выполнения заказов предприятиями, которые в этих компонентах нуждаются. Было отмечено, что в сети Интернет найти компоненты труда не составляет, однако большой проблемой является неподтвержденность качества этой ЭКБ и надежности предлагающей ее стороны. В этом контексте "ЭКБ МАРКЕТ» сможет стать для потребителей источником информации об остатках, достоверность которой гарантирована.

Далее сотрудниками ФГУП «МНИИРИП» был представлен ряд докладов, сосредоточенных на предлагаемых регламентах оказания конкретных услуг Многофункциональным центром радиоэлектроники в режиме одного окна, темы которых включали:

- получение разрешений на применение ЭКБ ИП;

- проведение испытаний ЭКБ и РЭА;

- включение изделий в Перечень ЭКБ, разрешенной для применения при разработке, модернизации, производстве и эксплуатации ВВСТ;

- получение свидетельств о квалификации поставщиков ЭКБ, аттестатов аккредитации испытательных лабораторий (центров), сертификатов соответствия системы менеджмента качества и аттестатов компетенции экспертов СДс «Электронсерт»;

- рассмотрение протокола согласования технических требований, подлежащих уточнению в ходе выполнения ОКР по заказу Минпромторга России;

- согласование программ и методик испытаний;

- согласование ТЗ на ОКР, выполняемых в инициативном порядке и по межзаводской кооперации;

- получение протоколов разрешения применения ЭКБ в режимах и условиях, отличных от ТУ;

- рассмотрение и согласование решений по организации дублирующего производства ЭКБ:

- согласование внесения изменений в КД;

- снятие изделий ЭКБ с производства;

- анализ отказов ЭКБ и РЭА образцов ВВСТ;

- проведение обязательной метрологической экспертизы технической документации разрабатываемых изделий ЭКБ и РЭА;

- оценку программно-аппаратных комплексов, основанных на отечественной ЭКБ.

Все доклады строились по единому сценарию и включали информацию о том, возможно ли получение услуги в электронном виде, на платной ли основе она будет оказываться, и о нормативных документах, на которых основана услуга. Также в докладах указывались сроки оказания услуги в соответствии с предлагаемым регламентом и приводился алгоритм выполнения услуги.

По словам П.П. Куцько, доклады были выстроены в порядке убывания количества голосов, полученных по итогам предварительного электронного голосования участников мероприятия, в рамках которого им было предложено указать наиболее актуальные для них темы. Отвечая на один из вопросов аудитории, П. П. Куцько также отметил, что с процедурами выполнения услуг, представленными в докладах, по большому счету, заявители не обязаны быть знакомы: их задача сдать правильно подготовленные документы в единое окно и получить результаты исполнения услуги через установленное время. Однако эти процедуры достаточно подробно представлены на конференции с тем, чтобы обеспечить максимальную прозрачность действий ФГУП «МНИИРИП» по рассмотрению документов и оказанию каждой услуги.

Следует отметить, что предлагаемые регламенты в своем большинстве предполагают весьма сжатые сроки оказания услуг. Так, срок оказания услуги по включению изделий в Перечень ЭКБ, разрешенной для применения при разработке, модернизации, производстве и эксплуатации ВВСТ, согласно предлагаемому регламенту, составляет не более 10 дней.

Также в рамках мероприятия были представлены доклады А. М.Шеманова, технического директора ООО "Глобал-Инжиниринг", о перспективной разработке компании - многопозиционном сканирующем зондовом микроскопе для неразрушающего диагностического контроля и Ю. В. Рубцова, генерального директора АО "ЦКБ "Дейтон", который рассказал участникам мероприятия о задачах создания, верификации и валидации математических моделей ЭКБ и проводимой компанией работе в этой области. Ю. В. Рубцов внес предложение о включении в перечень услуг создаваемого Многофункционального центра радиоэлектроники верификацию и валидацию моделей, которые могут проводиться на базе АО «ЦКБ «Дейтон».

По окончании докладов П.П. Куцько сообщил, что по результатам конференции будет принято решение, какие из представленных регламентов могут быть реализованы в предложенном виде, какие требуют доработки и по каким из них необходимо дополнительное обсуждение. Кроме того, на базе ФГУП «МНИИРИП» планируется проведение круглых столов с представителями отрасли для обсуждения вопросов, затронутых на конференции. П. П. Куцько призвал присутствующих вносить и свои предложения по темам круглых столов, а также пригласил чаще посещать сайт ФГУП «МНИИРИП», который теперь содержит много полезной информации. Как отметил директор института: "Сайт теперь работает для вас. Не для нас, а для вас". 